\title{
OS TEMAS EDUCAÇÃO, ESCOLA E CONHECIMENTO NAS LEIS E NAS PRÁTICAS MIDIÁTICAS BRASILEIRAS
}

\author{
JuVEnal Zanchetta Junior
}

\begin{abstract}
RESUMO: O presente texto investiga como os temas educação, escola e conhecimento são tratados na legislação maior e também nas práticas da mídia no Brasil. Entre as constataçôes está a contínua tergiversação do patronato midiático, comprometido apenas com açôes educativas pontuais e baseadas em demandas de mercado, algo possível em boa parte pelo caráter tangencial da legislação que relaciona educaçáa e mídia.
\end{abstract}

Palavras-chave: Educação. Escola. Legislação. Práticas midiáticas. Papel da família.

\section{THEMES SUCH AS EDUCATION, SCHOOL AND KNOWLEDGE IN BRAZILIAN LAWS AND MEDIA PRACTICES}

ABSTRACT: This paper investigates how education, school and knowledge are treated in Brazilian legislation and media practices. Among the findings is the constant avoidance of the media patronage, only committed to reporting isolated educational actions, and which are based on market demands. This is possible in large part by the tangential character of Brazilian legislation which relates education and media.

Keywords: Education. School. Media. Family role. Legislation. Media Practices.

\section{LES THÈMES DE L'ÉDUCATION, DE L'ÉCOLE ET DU CONNAISSANCE DANS LES LOIS ET DANS LES PRATIQUES DES MÉDIAS AU BRÉSIL}

RÉSUMÉ: Ce document examine comment les questions de l'éducation, de l'école et de la connaissance sont traitées dans la plupart des lois et aussi dans les pratiques des médias au Brésil. Parmi les résultats est la constante tergiversation du patronage des médias, engagé seulement avec des activités ponctuelles et en fonction des demandes du marché,

\footnotetext{
* Universidade Estadual Paulista "Júlio de Mesquita Filho", Programa de Pós-graduação em Educação. Assis, SP., Brasil. E-mail de contato: jzancheta@gmail.com.
} 
cela est possible, en partie, par le caractère tangentiel de la législation qui concerne l'éducation et les médias.

Mots-clés: Éducation. École. Législation. Rolê de la familie. Pratiques des Médias.

\section{Apresentação}

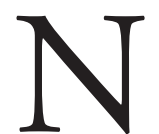

um vídeo com mais de 4 milhões de acessos, divulgado após a prova de química aplicada em 2013, uma jovem, com palavróes, mostrava sua indignação em relação a conteúdos sobre os quais ela dizia não ter nenhuma familiaridade ${ }^{1}$. Em 2013 e 2014, 29\% dos candidatos ao Exame Nacional do Ensino Médio (Enem) faltaram às provas (28\% em 2012 e 26\% em 2011). Tais situações compõem quadro ainda pouco claro, graças, entre outras razões, ao caráter iniciante dos estudos relacionados à juventude no país (ABRAMO, 1997; SETTON, 2009; HILSDORF; PERES, 2009), mas deixam entrever certa apatia dos jovens em relação a temas educacionais.

Levando em conta que parte do processo de socialização ocorre pelo legado às novas geraçóes, de valores culturais prestigiados por geraçóes anteriores, observamos como os temas educação, educação formal ou escola e conhecimento são tratados pela legislação maior e pelas práticas midiáticas.

O termo mídia abarca o conjunto de meios de comunicação (MC), como a televisão, o rádio e os jornais impressos (chamados meios de 'massa' ou 'mídia convencional'), cujas açôes, isoladas ou integradas, buscam alcançar públicos abrangentes e firmar posicionamentos. Maior atenção é dispensada à televisão e ao rádio, por serem objetos de concessão pública e também os meios mais presentes entre os brasileiros. (BRASIL, 2014) ${ }^{2}$ A mídia convencional continua representativa mesmo num cenário ofuscado por práticas que sobrevalorizam ações individuais e redes privadas. Em processo de adaptação ao fenômeno da popularização de novas ferramentas, as empresas de comunicação constituem estruturas abrangentes e integradas, que incluem novas e velhas tecnologias, formando circuitos de informação de grande envergadura, ajustados, por diferentes veículos e soluçóes, a públicos cada vez mais segmentados.

Assim, não é mais possível falar no caráter definitivo da TV Globo na proposição dos temas e dos pontos de vista predominantes na agenda pública do país, mas o circuito formado pelo grupo Globo Participaçóes (Globopar) tende a continuar decisivo. Com alguma discrepância entre os estudos (BIONDI; CHARÃO, 2008; GÖRGEN, 2011), em 2011, esse circuito contava com a TV 
Globo, cujo conteúdo era compartilhado por 126 emissoras de televisão, por canais fechados como GloboNews, Multishow, SporTV e GNT. Havia participação na Net Brasil, Net Serviços e Sky Brasil. Entre os cerca de 30 jornais ligados ao grupo, estavam $O$ Globo, Extra e Valor Econômico, a revista Época e outras 26. Concentravam-se as redes de rádio CBN AM (184 veículos associados), CBN FM (94 associados) e Globo AM (29 associados). O portal G1, a Agência Globo, os serviços de informação por demanda, empreendimentos fonográficos e cinematográficos também integravam a organização.

Um circuito de grande audiência serve de referência para os demais, numa época em que a informação se fragmenta e se difunde rapidamente em escala global, busca ineditismo (inerente à tradição da imprensa), e se abre à participação seletiva de personagens e de informaçôes provenientes de outros circuitos. A novidade se junta ao exercício sistemático de atualização e de configuração de modos próprios de tratar a informação, com personagens e sugestóes de edição que particularizam cada circuito. Tais estruturas mostram independência e capacidade para enfrentar assuntos espinhosos, mas também impóem temas, pontos de vista e matizes para o debate das coisas públicas. Sua influência pode ser vista na dinâmica da informação relativa às manifestações de junho de 2013: a informação e os temas mais acessados pelos brasileiros em redes como Twitter e Facebook foram justamente os produzidos por jornais, portais e noticiários de TV. (SOARES; SÁ, 2013) Se, num primeiro momento, a mídia convencional foi tomada de surpresa, ela se mostrou endereço decisivo para o curso das manifestaçóes.

Sobre o termo 'educação', concentramo-nos nas proposiçóes voltadas à educação formal ou à escola. Por escola e conhecimento, abarcamos os processos necessários ao domínio de códigos escritos, essenciais para a plena participação do sujeito na sociedade contemporânea (SAVIANI, 2013), e ainda o desenvolvimento individual em suas dimensôes epistêmicas, éticas e estéticas. (GOERGEN, 2013) Dever constitucional do Estado, a educação tem na escola a instituição responsável por essa formação, mas os demais agentes públicos devem contribuir para tanto. Canais de televisão (abertos e fechados) e de rádio, e o espaço de telefonia (sobre o qual se estabelece a internet) são concessóes públicas ${ }^{3}$. O Regulamento dos Serviços de Radiodifusão (RSR), norma maior do setor, cuja configuração foi estabelecida em boa parte pelo próprio patronato midiático (LIMA, 2012) destaca a responsabilidade dos $\mathrm{MC}$ :

Art. $3^{\circ}$ : Os serviços de radiodifusão têm finalidade educativa e cultural, mesmo em seus aspectos informativo e recreativo, e são considerados de interêsse nacional, sendo permitida, apenas, a exploração comercial dos mesmos, na medida em que náo prejudique êsse interêsse e aquela finalidade. (BRASIL, 1963) 
Afora a questão legal, a defesa da educação como dever de Estado é princípio comum às diferentes correntes liberais (GOERGEN, 2013) e o liberalismo, por seu turno, apesar de ter se desenvolvido no Brasil de maneira sempre adaptada aos interesses de grupos econômicos com maior poder (SANTOS, 1978), não deixa de ser tema caro à mídia convencional. ${ }^{4}$

Sublinhe-se, ainda uma vez, o objetivo deste trabalho: a observação dos temas afins à educação formal a partir da legislação maior e também a partir de práticas midiáticas no país. Optou-se também por comentário sobre o papel da família - além da escola e da própria mídia, um dos mais tangíveis agentes corresponsáveis pela educação entre aqueles aventados pelas normas oficiais e pelo discurso empresarial. Não se discute o papel histórico efetivamente exercido pela família no processo de educação formal, mas sim o modo como o discurso oficial a percebeu. Também não é possível tratar dos modos pelos quais a escola se ajusta e desenvolve açóes próprias para o enfrentamento da mídia.

\section{Legislação}

A Constituição de 1988 foi a primeira a propor associação, mesmo vaga, entre a tarefa de educação e a ação da mídia. Os artigos 205 a 214 definem a educação como 'direito de todos e dever do Estado e da família', bem como a responsabilidade direta da escola por essa educação. A Carta é menos objetiva quanto ao papel dos demais agentes: a segunda parte do enunciado do artigo 205 responsabiliza entidade genérica, ao afirmar que a educação 'será promovida e incentivada com a colaboração da sociedade'.

Os artigos referentes à Cultura conferem ao Estado a obrigação pela preservação e promoção do 'patrimônio cultural brasileiro', cuja descrição inclui 'criaçôes científicas, artísticas e tecnológicas' (art. 216, inciso III). Porém, o texto solicita apenas a 'colaboração da comunidade' (art. 216, parágrafo 10). Entre as 53 metas do Plano Nacional de Cultura, uma (19a) trata da promoção do conhecimento, por meio de bolsas concedidas a pessoas que se destaquem 'por açóes de fomento à pesquisa, formação e difusão do conhecimento'. 5

O capítulo alusivo à comunicação social traz afirmação categórica sobre a relação entre Estado, mídia e educação: emissoras de rádio e de televisão devem dar 'preferência a finalidades educativas, artísticas, culturais e informativas' (art. 221, Inciso I). No entanto, esse artigo, bem como a maioria dos tópicos relativos à comunicação social continua com pouca regulamentação por leis complementares. (LIMA, 2012)

Nas leis que regulam a educação, a associação direta entre mídia e educação é limitada, como no caso da atual Lei de Diretrizes e Bases da Educação, que 
prevê o concurso dos serviços de radiodifusão comercial apenas para a educação a distância (art. 80). ${ }^{6}$ No Plano Decenal de Educação para Todos, de 1993, havia referência clara ao papel dos MC:

A mobilização social em torno da qualidade e equidade da educação básica exige, ainda, participação organizada dos meios de comunicação de massa, na difusão dos debates públicos sobre o tema e na criação de clima favorável às mudanças educacionais que o país requer. $(\mathrm{p} .44)^{7}$

No Plano Nacional de Educação de 2001 (Lei 10.172/01), a referência direta restringia-se ao ensino a distância, mas havia a sugestão de "[...] enviar ao Congresso Nacional [...] proposta de regulamentação da reserva de tempo mínimo, sem ônus para o Poder Público, para transmissão de programas educativos pelos canais comerciais de rádio e televisão, inclusive em horários nobres"! (tópico 6.3). No Plano mais recente (Lei 13.005/14), já não há menção à mídia.

$\mathrm{O}$ concurso dos $\mathrm{MC}$ está em esboço nas leis que tratam da infância e da juventude. O Estatuto da Criança e do Adolescente (ECA) enuncia primeiro a família e entidades pouco concretas como 'comunidade' e 'sociedade em geral', e por último o 'poder público' como responsáveis pelo direito à educação (art. 4). Diferentemente do que ocorre em democracias como as europeias, o ECA não se posiciona quanto à publicação de notícias e de propagandas potencialmente abusivas à criança e à juventude. (MENDEL; SALOMON, 2011) No tópico sobre o direito à educação, à cultura, ao esporte e ao lazer, o ECA reproduz a Carta de 1988, retirando do texto responsabilidades aos agentes de Estado (art. 53). Os artigos 74 e 76, ao tratarem da exposição de crianças e jovens a conteúdos midiáticos, ao menos levaram à qualificação dos programas por faixa etária, estabelecida pelo governo federal nos anos 2000.

O Ministério da Justiça, responsável pela classificação indicativa dos programas de televisão, de filmes e de games, restringe sua análise aos temas 'violência', 'sexo' e 'drogas'. Há significativo avanço em relação ao padrão de censura realizado no Brasil do século 20 , então pautado pela vaga ideia de preservação da moral, dos costumes e dos valores políticos e ideológicos adequados aos governos de diferentes épocas. (GOMES, 2013) A ênfase atual não destoa do trabalho realizado por países referenciais ao Brasil, como Estados Unidos, Inglaterra, Espanha, França e Portugal. Nestes últimos, porém, tal classificação se dá por organismos independentes, com certo consenso nacional ou regional, mesclando interesses públicos e privados. (BUCCI; KHEL, 2006) No Brasil, a classificação, embora mediada por organismo público, segue a reboque da regulação praticada pelos MC. E estes últimos, por sua vez, constroem sua programação tomando como 
referência os números de audiência, utilizando formatos de programas pouco arrojados, como se vê no desabafo de Jorge da Cunha Lima:

Todas as televisôes produzem o mesmo jornalismo, as mesmas casas dos artistas; todas as televisóes, se tivessem dinheiro, produziriam as mesmas novelas. [...] Não há diversidade. Por quê? Porque as regras de mercado que sustentam as sacrificadas televisôes brasileiras... [...] Na verdade, as televisôes produzem o mesmo conteúdo para 100 milhóes de pessoas. E essa inexistência de paradigmas alternativos é a mais cruel das concentraçóes. (CCS, 2004)

O manual de classificação indicativa (ROMÃO et al., 2006), ao restringir a avaliação, sacramenta a predominância dos mesmos e apelativos assuntos na programação, em detrimento de outros temas, que figuram na condiçáo de 'atenuantes' ou 'agravantes' para diminuir ou aumentar a faixa etária sugerida para a assistência. Educação formal e escola não são citadas. $\mathrm{O}$ único tema 'atenuante' que se aproxima da questão educacional é a valorização do 'conhecimento e de habilidades cognitivas'.

O Estatuto da Juventude (Lei 12.852/2013) restringe à instituição escolar a tarefa de educação formal, sem mencionar papel para a mídia (Seção II, Do Direito à Educação). Já para a consecução dos 'direitos culturais' dos jovens, incumbe-se não a mídia, mas o Poder Público de promover 'programas educativos e culturais' (art. 22, inciso VI).

O Marco Civil da Internet (MCI) (Lei 12.965/2014) também é tímido. O debate realizado no Congresso Nacional provocou polêmica mais por conta da movimentação política, por interesses comerciais e pela busca de mecanismos de proteção do usuário/cliente. No texto original ${ }^{8}$, a ideia de educação associada à internet mostrava-se tênue, mas sugeria relação direta entre o dever do Estado e "[...] a promoção da cidadania, da cultura e do desenvolvimento tecnológico [...]." (art. 21). No texto da lei, apesar de se conferir papel mais concreto ao Estado ('capacitar' os estudantes para uso da rede, de acordo com o art. 26), tal determinação está diminuída (pois reduz o espectro de ação do Estado a uma só dimensão de formação) e imprecisa (pois valida qualquer ação que lembre a ideia de instrução).

Como exemplo de ação (direta) que os governos (sem mencionar outras instituiçôes) poderiam promover, citem-se os sítios oficiais. Os conteúdos desses sítios, como os 'serviços' e as informações técnicas, são acessíveis apenas a iniciados e continuam intransponíveis para o leitor comum, entre eles os estudantes. Se, na proposta original do MCI, havia terreno para pensar as páginas do Ministério da Educação (MEC) ou as do Ministério da Fazenda, entre outras, como potenciais espaços de interlocução com os jovens (ocupando-se talvez o lugar hoje conferido 
à exaustiva propaganda das açóes de governantes), no texto definitivo tal hipótese se esvai.

Finalmente, ao perpetuar a regra da laicidade do ensino escolar e, ao mesmo tempo fazer vistas grossas para os programas confessionais (responsáveis pela maior parcela da programação na televisão aberta ${ }^{9}$ ), o país desconsidera a mídia como agente público, desobrigando-a da tarefa educacional. Programas religiosos somaram, em 2013, quase $15 \%$ do total da programação da TV aberta no país, ficando à frente de todos os demais gêneros.

\section{Mídia: normas e propostas}

No Código Brasileiro de Telecomunicações (Lei federal 4.117/62), regulador dos serviços e das regras de concessão, o tema da educação aparece na referência genérica a supostos abusos à 'moral familiar, pública ou aos bons costumes' (artigo 53). No RSR, embora se explicite a finalidade educativa e cultural da radiodifusão no país, não há orientação específica. Como as antecessoras, as leis posteriores privilegiaram o patrimonialismo nas concessóes. Alterado em 1983, o RSR incluiu a obrigatoriedade de veiculação de 'programas educativos' (Decretos federais 88.066/83 e 88.067/83). Entretanto, a 'cota educativa' ficou restrita a cinco horas de programação semanal (em horário indefinido), sem que se estabelecesse o conteúdo exibido.

Entre as normas recentes, a lei que dispóe sobre a organização dos serviços de telecomunicaçóes (Lei 9.472/97) deixou de lado o conteúdo proposto pelas emissoras (JAMBEIRO, 2000), algo que seria enfrentado pela Lei 12.485/11. Esta última, por sua vez, mostrou-se rumorosa, mas também por razões de mercado, ao permitir a entrada de empresas de telefonia na competição por assinantes e ao fomentar canais e produtores de televisão com atuação no Brasil, aumentando a parcela de 'conteúdo nacional' no total de veiculaçóes da televisão paga. Os 'conteúdos nacionais ${ }^{\prime}{ }^{10}$, por seu turno, além de genericamente definidos como aqueles que se ponham em 'língua portuguesa' e tratem da 'cultura brasileira', tendem a não destoar do perfil da programação veiculada até hoje, ao serem traduzidos como obras de ficção, documentários, animaçóes, reality shows(!), videomusicais e variedades $^{11}$. O próprio órgão regulador ressalta que "[...] nenhum canal terá que mudar o perfil de sua programação para cumprir as obrigaçóes de veiculação de conteúdos nacionais $[\ldots]$ "... ${ }^{12}$

Os canais educativos oferecem alternativa restrita. Mantida desde a origem (Decreto-lei 236/67) pelo subsídio estatal (com regras mais flexíveis desde os anos 1980) e premida pelo modelo comercial das redes privadas, a televisão educativa sempre teve atuação discreta. A carência histórica de alternativas entre 
tais canais, o mercado e a sociedade, na prática, além de privilegiar, mais uma vez, as redes privadas (JAMBEIRO, 2000), reforça a dependência conjuntural e política dos canais educativos. Mesmo com trajetória reconhecida no país e no exterior, a TV Cultura, em São Paulo, é exemplo dessa dependência. (LEAL FILHO, 2009) A repercussão tímida de iniciativas governamentais, como a da criação da Rede Pública de TV (RPTV) nos anos 1990 e a da Empresa Brasil de Comunicação (EBC), em 2009, responsável pela TV Brasil e pela TV NBR, é outro sinal da limitação.

Iniciativa promissora para aproximar o cenário educacional formal da dinâmica dos canais de televisão seria realizada em 1996, com a criação da TV Escola. Porém, mesmo próximo dos currículos regulares, depois de duas décadas, o canal estatal: a) esbarrou na falta de experiência dos agentes (de produtores a professores) em relação a esse tipo de 'ferramenta pedagógica' (BELLONI, 2003); b) concentra esforços no apoio pedagógico de um público delimitado (professores), fazendo predominar o tom professoral; ${ }^{13}$ c) está disponível por antenas parabólicas, na tevê por assinatura ${ }^{14}$ e na internet, contando com audiência discreta.

Iniciativas privadas, como o canal Futura, buscam alternativas para falar mais de perto com os estudantes. Porém, além de visão edulcorada do cenário escolar, reduzindo os desafios da educação à afetividade, ao voluntarismo e à criatividade dos agentes escolares (PARAÍSO, 2006), a Fundação Roberto Marinho, um dos principais patrocinadores desse canal, investe em caminhos próprios de formação, operando apenas com redes escolares que aceitem projetos e temas encampados por ela. ${ }^{15}$

Outro projeto representativo da Globopar é o hoje chamado Telecurso, iniciativa em parceria com o setor industrial, abarcada pelo Governo Federal. Desenvolvido desde a década de 1970, o Telecurso moldou-se como alternativa de ensino a distância, voltado para a educação supletiva e técnica, atendendo a regióes com menos escolas regulares ou a demandas localizadas do mundo empresarial. Reproduzindo modelo próximo do ensino convencional, acrescido dos recursos e da técnica utilizada pela televisão comercial, o Telecurso tem sua permanência em boa parte explicada pelo pragmatismo: sua finalidade certificadora, chancelada por organismos oficiais.

Programas de difusão da ciência e tecnologia, presentes em canais abertos e fechados, optam pela agilidade e pela dinâmica da reportagem. Entretanto, além de pontuais, investem menos na difusão dos processos científicos e de aprendizagem do que em iniciativas acadêmicas específicas e de maior apelo popular.

Já programas com sucesso de crítica ou de audiência em diferentes momentos, como Vila Sésamo, Sítio do Pica-pau Amarelo (em suas diferentes versóes), Rá-tim-bum e Cocoricó, entre outros, mostram que existe espaço para açóes que caminhem em paralelo com a educação formal. Mas, além de raras, elas esbarram 
no caráter circunscrito de sua circulação, por conta da exibição em canais com menor audiência ou por alcançar faixas etárias específicas.

A limitação de público é também característica de revistas pedagógicas e de divulgação científica. Entre as revistas pedagógicas, o modelo mais representativo está na Nova Escola, publicada desde 1986. Em parte subsidiada por governos, com assinaturas ou com a compra de espaços de publicidade, esta revista (e outras, surgidas mais tarde) volta-se aos professores e, sobretudo, àqueles que se alinham com as propostas pedagógicas presentes nas diretrizes nacionais para a educação (como em relação à perspectiva construtivista). Revistas como Superinteressante e Galileu, por seu turno, estão entre as estratégias efetivas para a aproximação entre os universos da ciência e o da juventude. Mas, além de também restritas em termos de público, sugerem imagem até certo ponto deslocada da ciência, por conta de opçóes como: a) temas mais apelativos; b) resultados categóricos e menos a divulgação de processos de pesquisa; c) simplificação excessiva de formulações, que acabam reduzidas ao mínimo necessário para a compreensão da linha narrativa. (NOCCIOLI; PAES, 2012)

Quanto aos jornais impressos, destaque-se projeto de maior envergadura, voltado à formação de leitores de jornais: o Programa Jornal e Educação. Criada nos anos 1980 pelo jornal Zero Hora, a iniciativa foi encampada pela ANJ e, em 2013, havia cerca de 50 empresas jornalísticas empenhadas em programas próprios de formação de leitores. No entanto, essa iniciativa (na verdade a somatória de diferentes propostas desenvolvidas por jornais diversos) persiste em função do marketing das empresas (interessadas em formar leitores de seus produtos) e da perseverança de alguns jornais e jornalistas, e menos por conta de uma proposta integrada.

As organizaçóes midiáticas ${ }^{16}$ também se esquivam de compromisso determinante. Ações também fluidas norteiam as práticas midiáticas, como no caso das regras do Conselho Nacional de Autorregulamentação Publicitária (Conar), organismo de análise de conteúdo oriundo das empresas de comunicação. Embora a publicidade ocupe $25 \%$ do total da programação do rádio e da televisão, o Código Brasileiro de Autorregulamentação Publicitária (CBAP) sugere que a tarefa de educar cabe à família, aos 'educadores', às 'autoridades' e à 'comunidade'. Ao mencionar propagandas para crianças e jovens, o CBAP evoca platitudes:

I - Os anúncios deverão refletir cuidados especiais em relação a [sic] segurança e às boas maneiras e, ainda, abster-se de:

a. desmerecer valores sociais positivos, tais como, dentre outros, amizade, urbanidade, honestidade, justiça, generosidade e respeito a pessoas, animais e ao meio ambiente;

$[\ldots]$ 
II - Quando os produtos forem destinados ao consumo por crianças e adolescentes seus anúncios deverão:

a. procurar contribuir para o desenvolvimento positivo das relaçóes entre pais e filhos, alunos e professores, e demais relacionamentos que envolvam o público-alvo... (CBAP, s/d, artigo 37) [Grifos nossos]

O Código de Ética da Radiodifusão Brasileira, proposto pela Abert desde 1993 recorre ao tema da educação em casos de punição:

Julgadas culpadas, as emissoras [...] serão condenadas a divulgar, no mínimo seis e no máximo vinte mensagens de 30 segundos rotativa e diariamente, durante uma semana, no mínimo, e um mês no máximo, para divulgação de campanhas educativas. Nas reincidências a pena será acrescida, de acordo com a gravidade de $25 \%$ até $100 \%$ quanto ao número e duração do tempo das inserçôes. (ABERT, 1993, art. 27)

A posição fugidia da mídia em relação à educação faz parte da estratégia de contínuo adiamento da discussão sobre uma política de comunicação para o país (REBOUÇAS, 2006), algo que poderia incluir enfrentamento mais claro sobre temas ora observados.

\section{Família em cena}

Desde a Constituição de 1891, o Estado assumiu, ainda que de maneira pouco programática, a responsabilidade pela formação educacional dos cidadãos, e essa tarefa, em sua maior parte, coube à escola e não à família. Apesar de não haver referência explícita ao tema, ao proclamar-se a laicidade da educação, diminuiu-se diretamente a influência da Igreja e indiretamente também a da família sobre a formação dos jovens, pois os princípios familiares estavam pautados pelos mesmos princípios religiosos (bem mais do que por princípios políticos).

Desde o século 19, o projeto civilizatório do país, embora diverso e com as mais diferentes coloraçóes políticas, sempre tomou a educação formal como âncora, observando a família de maneira secundária, como se vê em estudos revisionais clássicos. (ROMANELLI, 1986; PATTO, 1993; WEREBE, 1993; RIBEIRO, 1998) O Manifesto dos Pioneiros da Educação Nova sobrepóe o papel transformador da escola ao conservadorismo de instituiçóes até então preponderantes e responsáveis pelo atraso do país, como a própria família: 
A transformação de nosso regime educacional [...] não tem apenas, por si, o espírito atual e vivo que lhe está imanente, e os fundamentos científicos e filosóficos em que se apoia, mas a consciência do papel que a escola deve desempenhar, não só na formação do espírito e da unidade nacional, como na aproximação dos homens e no restabelecimento do equilíbrio social, realizando pela integração da escola na sociedade (socialização da escola) a integração, no grupo e na vida social, do indivíduo cada vez mais isolado entre um grupo familiar que se atrofia e se desagrega e uma sociedade tornada imensa. (AZEVEDO, 2010 [1932], p.29)

A consolidação da Pedagogia nas primeiras décadas do século 20 acelerou o distanciamento. Na publicação acadêmico-pedagógica mais longeva da educação brasileira, a Revista Brasileira de Estudos Pedagógicos (RBEP), desde os anos 1940 até os anos 1960, as referências à família em geral são prescritivas, visando à mudança de hábitos, concentrando-se em fatores biológicos, como a higiene e a 'saúde mental', e numa sorte de valores morais, predisponentes para auxiliar as crianças e jovens no espaço de educação efetiva, a escola. A família e, principalmente, a família de baixa renda, moradora da zona rural e da periferia das grandes cidades, foi tomada como um dos fatores decisivos para o fracasso dos estudantes. Note-se a impressão de Cardoso (1949, p. 81-2), ao tratar dos efeitos do 'ambiente' na formação de crianças da periferia da cidade do Rio Janeiro:

Em casos como esses [marcados pela miséria e pela falta de
recursos], o meio familiar, em que a criança passa a maior parte
do tempo, é, em tudo, a antítese do meio escolar. O que a escola
procura construir a família destrói, num momento se reduz a
pó. Os exemplos vivos e flagrantes insinuam-se na carne, no
sangue das crianças, ditando-lhes formas amorais de reação,
comportamentos antissociais.

Entre os anos 1960 e 1980, na versão mais tecnicista do escolanovismo, desprezavam-se os fatores sociais no cenário da aprendizagem.

A proposta de reabilitação da família como instituição corresponsável pela educação formal chegaria de maneira decisiva nos anos 1990, em meio à aceleraçáo do processo de universalização do ensino fundamental e ao debate sobre reformas estruturais na escola brasileira. Mesmo assim, a ideia de se conferir papel pronunciado para a família gerou ceticismo e resistência, tendo sido interpretada como incentivo à privatização da Educação Básica. (TORRES, 1996; LAUGLO, 1997)

Finalmente, exemplo de outra área pode ilustrar o papel programático secundário atribuído à família. Apenas na Carta de 1988 há a sugestão de espaço 
para família na formação das crianças e jovens, conferindo a ela 'corresponsabilidade' na garantia 'do direito à educação, ao lazer, à cultura e à dignidade' (art. 227), algo que aparece mais definido no Código Civil de 2002 (Lei 10.406/02). Isso ajuda a explicar porque o Ministério da Justiça somente na década passada incluiu a família como agente na tarefa de exercer a 'classificação indicativa'. (ROMÃO et al., 2006; BUCCI; KHEL, 2006)

\section{Considerações finais}

O quadro esboçado não abarca todas as normas, veículos e ferramentas que inspiram ou relacionam educação, escola, conhecimento e mídia. Não se pretendeu discutir o mérito das normas, nem suas possibilidades de interpretação, mas tão somente destacaram-se citaçóes mais evidentes, em que os temas em estudo aparecem relacionados. Chega-se a um quadro ainda em esboço, mas sugestivo de associação cada vez mais rasa. A questão aparece hesitante na legislação, pouco circunscrita em termos conceituais e inespecífica em termos de papeis aos agentes que devem auxiliar a escola na missão de educar.

A hesitação pode ser observada em outros exemplos. Mesmo reconhecendo que "[...] as telecomunicaçóes são mais causa do que consequência do desenvolvimento de um país [...]”, a Agência Nacional de Telecomunicaçóes $(\text { Anatel })^{17}$, que poderia exercer algum papel de fomento, não tem a educação entre suas preocupações. O Conselho de Comunicação Social do Congresso Nacional, criado em 1991, embora contando com representação dos principais setores da comunicação do país, segue com papel decorativo. Um único projeto (PL$7450 / 10)^{18}$, em tramitação na Comissão de Educação da Câmara dos Deputados (CE), discute o papel da mídia na educação nacional. Trata-se do pedido de inclusão da disciplina "Leitura e Educação para as Mídias" no currículo escolar, atento apenas à necessidade de se prevenir a assistência quanto ao consumo desenfreado. Até o início de 2014, aquele projeto disputava atenção com outras 400 propostas, entre elas 34 projetos de disciplinas ou de temáticas para serem incluídas no currículo, como "Educação para o Pensar" (PL-2240/2007) e o ensino de Esperanto (PL-6162/2009).

O distanciamento entre o princípio republicano da Educação e a mídia suscita explicaçóes que vão além da ideia de redução do tamanho do Estado e do triunfo da livre-iniciativa, argumentos frequentes nas interpretaçóes sugeridas para o liberalismo dos dias de hoje. Entre as estratégias de afunilamento de conteúdos promovidas pelos maiores circuitos midiáticos, há alguma orientação quanto à educação formal. Iniciativas privadas, com ou sem apoio público, independentemente do mérito individual, exercem funçóes que podem ser delineadas. Entre outras, eis algumas delas: 
a) Complemento: incluem-se aqui projetos de apoio educacional, de canais como Futura e revistas pedagógicas a especialistas voltados à orientação técnica. A atualidade, a visibilidade e o dinamismo desses projetos são fatores decisivos para criar autoridades escolares fora da escola;

b) Crítica: afora o exercício de fiscalização e de problematização da coisa pública - inerente ao papel da mídia -, reúnem-se neste grupo iniciativas que propóem alternativas para a melhoria da educação formal. Para tanto, convocam-se economistas, cientistas políticos, jornalistas, consultores, empresários, líderes de organizaçóes não governamentais, entre outros profissionais distantes da escola e da pesquisa na área de Educação;

c) Substituição: a ação da mídia ajuda a consolidar políticas públicas. A maior atenção com a Educação Básica, as ênfases na racionalização e no desempenho quantitativo e qualitativo, a ideia de melhoria das competências do professor, por exemplo, foram temas regulares na imprensa nos anos 1990 e transformaram-se em propostas políticas na década seguinte. ${ }^{19}$ Hoje, parte do discurso político que aponta para a mudança do perfil da ação estatal para a educação (de um Estado educador a um Estado supervisor e avaliador), passa pelas páginas dos principais jornais e revistas. $\mathrm{O}$ contínuo ranqueamento de escolas e Estados, com a discussão centrada nas razóes para o sucesso e o planejamento de desempenhos futuros, ocupa boa parte do espaço destinado pela imprensa à educação. ${ }^{20}$

Há, portanto, sentido convergente na ação da mídia, que inclui o isolamento da escola de que dispomos hoje, e a busca por novos modelos, que secundarizam a opinião de pesquisadores da área de educação.

O governo chinês colocou astronautas na função de professores, em plena missão espacial, exibindo-os ao vivo em programa para as escolas iniciais, para incentivar o estudo de ciências. Já a primeira aventura sideral de um brasileiro consumiu US\$10 milhóes dos cofres públicos, sem qualquer projeto de divulgação da ciência, e deixou como legado apenas a promoção do próprio astronauta, e dos produtos anunciados por ele, de comida dietética a travesseiros. (NERY, 2013) Não se sugere aqui programas pedagógicos no horário nobre, mas há inúmeras alternativas intermediárias entre a experiência chinesa e a brasileira. À exceção de soluçóes voluntaristas possíveis à escola e à família, as proposiçóes mais abrangentes dependeriam de consensos políticos mais amplos.

Os meios de comunicação podem ser fundamentais para tornar o conhecimento sistematizado atraente, interferindo em situaçáo comumente explicada de maneira primária: a culpa pelo desinteresse seria da escola e dos professores, dos próprios jovens ou de suas famílias, como se estes agentes fossem os únicos res- 
ponsáveis pela tarefa de integrar valores escolares (abstratos, mediatos e de longo curso), com o mundo imediato das preocupaçôes juvenis, familiares, da vida social e do consumo. Mesmo no cenário contemporâneo de comunicação fluida, onde se destacam novos e individualizados canais, e onde se entrecruzam mais agentes, a mídia convencional pode ajustar o foco de mobilizaçóes paroquiais e difusas, de modo a consolidar temas educacionais na produção da cultura popular. Se a tendência à homogeneização temática, por parte da mídia, foi capaz de reabilitar lutas violentíssimas e sanguinárias, vendendo-as como produto nobre, os temas educacionais têm alguma chance de êxito.

\section{Notas}

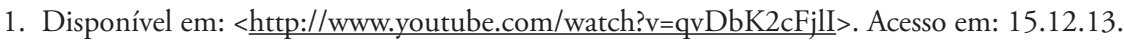

2. Segundo dados oficiais, a televisão continua a ser o MC mais comum, acessada por $97 \%$ da população (91\%, dispóem de TV aberta e 31\% dispõem de TV paga), seguida pelo rádio (61\%), internet $(47 \%)$, jornais $(25 \%)$ e revistas impressas $(15 \%)$. A televisão é o meio preferido para $76 \%$ dos brasileiros, seguida por internet $(13 \%)$ e rádio $(8 \%)$.

3. Jornais impressos não são objeto de concessão, mas, ligados a circuitos maiores, eles se beneficiam de estruturas de apoio baseadas em canais cedidos pelo Estado.

4. Basta observar o texto que traduz a 'missão' da Associação Nacional de Jornais (ANJ). Disponível em $<$ http://www.anj.org.br/missao $>$. Acesso: 15.03.2014.

5. Disponível em: <http://www2.cultura.gov.br/site/wp-content/uploads/2013/02/2\%C2\%AA-edi\%C3\%A7\%C3\%A3o-As-Metas-do-Plano-Nacional-de-Cultura-vers\%C3\%A3o-final-espelhado-para-o-site-19MB.pdf $>$. Acesso em 04.01.14.

6. A lei 5.692/71 solicitava os serviços de radiodifusão somente para a educaçáo supletiva.

7. Disponível em: <http://www.dominiopublico.gov.br/download/texto/me001523.pdf>. Acesso: 10.01.14.

8. Projeto de lei $\mathrm{n}^{\circ}$ 2.126/2011. Disponível em: <http://edemocracia.camara.gov.br/web/marco-civil-da-internet>. Acesso em 16.03.2014.

9. Dados disponíveis em: <http://www.direitoacomunicacao.org.br/content.php?option=com content\&task=view\&id=9846>. Acesso em: 20.03.2014.

10. Apostos na Instrução Normativa n. 100, da Ancine, que regulamenta dispositivos da Lei $12.485 / 11$.

11. Trata-se da definição de 'espaço qualificado' (IN 100, art. $8^{\circ}$ ).

12. Disponível em <http://www.ancine.gov.br/sala-imprensa/noticias/nova-lei-da-tv-paga-estimula-concorr-ncia-e-liberdade-de-escolha $>$. Acesso em: 29 dez. 2014.

13. Tom mais acadêmico pode ser observado em proposiçóes como as da TV Univesp, ligada ao governo do Estado de Sáo Paulo, em que cursos originalmente voltados ao ensino de graduação são editados para públicos mais amplos.

14. Projeto para se oferecer a TV Escola com sinal aberto foi apresentado em 2012 (PL 3.333/12) e arquivado nos termos do Artigo 105 do Regimento Interno da Câmara dos Deputados, em 31 de janeiro de 2015. 
15. Cf. texto introdutório ao tema 'Escola', no sítio da Fundação Roberto Marinho. Disponível em: <http://www.frm.org.br/main.jsp?lumChannelId=4028E49E30E708BF0130E723269301B4 >. Acesso em: 30.10.2012.

16. Entre as principais, além da Abert e ANJ, estão a Associação Brasileira de Radiodifusores (Abra); a Associação Brasileira de Televisão por Assinatura (ABTA); a Associação Nacional de Editores de Revista (Aner); a Associação Brasileira de Agências de Publicidade (Abap); e a Associação Brasileira de Anunciantes (ABA).

17. Disponível em: <http://legislacao.anatel.gov.br/resolucoes/2008/11-resolucao-516>. Acesso em 27.03.2014.

18. Em 22 de maio de 2015 foi designado como relator o Dep. Celso Jacob (PMDB-RJ).

19. Sabino Filho salienta como tais características, inspiradas em organismos multinacionais, foram discutidas a partir das páginas de revistas de como Veja - e não a partir de negociaçáo com os meios educacionais (SABINO FILHO, G. A boa escola no discurso da mídia. São Paulo: Unesp, 2005).

20. No início de 2014, já havia pelo menos quatro iniciativas inscritas na CE, propondo a divulgação externa de desempenho escolar, como a sugestão de fixação de placas com os indicadores na porta das escolas.

\section{Referências}

ABERT. Associação Brasileira de Emissoras de Rádio e Televisão. Código de ética da radiodifusão brasileira. Brasília: Abert, 1993.

ABRAMO, H. W. Consideraçôes sobre a tematização social da juventude no Brasil. Revista Brasileira de Educação, Anped, 1997.

AZEVEDO, F. et al. Manifestos dos pioneiros da Educação Nova (1932) e dos educadores 1959. Recife: Fundação Joaquim Nabuco, Editora Massangana, 2010. Disponível em: <http:// www.dominiopublico.gov.br/download/texto/me4707.pdf>. Acesso em 30.04.2013.

BELLONI, M. L. A televisão como ferramenta pedagógica na formação de professores. Educação \& Pesquisa, n.2, São Paulo, jul./dez. 2003.

BIONDI, A.; CHARÃO, C. Terra de gigantes. Revista da Adusp, n. 42, jan. 2008. Dispo-

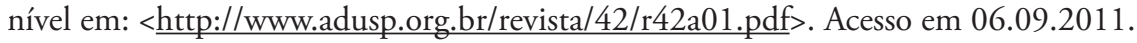

BRASIL. Ministério das Comunicaçóes. Decreto n. 52.795, de 31 de outubro de 1963. Aprova o Regulamento dos Serviços de Radiodifusão. Brasília, Diário Oficial da União, 12 de novembro de 1963. Disponível em: <http://www.mc.gov.br/legislacao/por-ano/ anos-anteriores/decreto-n-52-795-de-31-de-outubro-de-1963>. Acesso em: 15.12.2013.

. Secretaria de Comunicação Social. Pesquisa brasileira de mídia 2014: hábitos de consumo de mídia pela população brasileira. Brasília: Secom, 2014. Disponível em:

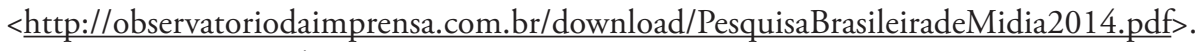
Acesso em 15.03.2014.

BUCCI, E.; KHEL, M. R. Deve o Estado classificar indicativamente o entretenimento a que o público tem acesso? In: ROMĀO, J.E.E. et al. Classificação indicativa no Brasil: desafios e perspectiva. Brasília: Secretaria Nacional de Justiça, 2006. 
CARDOSO, O.B. O problema da repetência na escola primária. Revista Brasileira de Estudos Pedagógicos, v. XIII, jan./abr. 1949.

CBAP. Código Brasileiro de Autorregulamentação Publicitária. Conselho Nacional de Autorregulamentação Publicitária. Disponível em: <http://www.conar.org.br/>. Acesso em 31.05.2013.

CCS. CONSELHO DE COMUNICAÇÃO SOCIAL. Concentração da Mídia: Debates no Conselho de Comunicação Social. Brasília: Congresso Nacional, 2004. Disponível em: $<$ http://www.observatoriodaimprensa.com.br/download/CCS Concentracao da Midia. pdf>. Acesso: 15.03.2013.

GOMES, M. R. Sobre supervisão e controle: um exercício em torno da classificação indicativa. Revista Matrizes, v.7, n.1, 2013.

GOERGEN, P. A educação como direito de cidadania e responsabilidade do Estado. Educ. Soc., v. 34, n.124, p.723-742, jul./set. 2013.

GÖRGEN, J. (Coord.). Projeto Os Donos da Midia. Setembro, 2011. Disponível em $<$ http://donosdamidia.com.br>. Acesso em 07.09.2011.

HILSDORF, M. L. S.; PERES, F. A. Estudos históricos sobre a juventude: estado da arte. In: SPOSITO, M. P. O estado da arte sobre juventude na pós-graduação brasileira: Educação, Ciências Sociais e Serviço Social. Belo Horizonte: Argumentum, 2009. Disponível em $<$ http://www.emdialogo.uff.br/sites/default/files/EstadoArte-Vol-2-LivroVirtual.pdf $>$. Acesso em: 20.12.2013.

JAMBEIRO, O. Regulando a TV: uma visão comparativa no Mercosul. Salvador: EDUFBA, 2000. Disponível em: <http://books.scielo.org/id/qgfnd/pdf/ jambeiro-9788523208790-06.pdf>. Acesso: 28.04.2013.

LAUGLO, J. Crítica às prioridades e estratégias do Banco Mundial para a Educação. Cadernos de Pesquisa, n. 100, mar. 1997.

LEAL FILHO, L. Percalços da TV pública: o caso da TV Cultura. Estudos Avançados, São Paulo, v. 23, n.67, 2009.

MENDEL, T.; SALOMON, E. O ambiente regulatório para a radiodifusão: uma pesquisa de melhores práticas para os atores-chave brasileiros. Comunicação e Informação. Brasília, Unesco. Série Debates CI, n. 7, fev. 2014. Disponível em: <http://www.observatoriodaimprensa.com.br/download/O ambiente regulatorio PORT.pdf $>$. Acesso: 05.05.2014.

NERY, N. 'Astronauta' vira socialista e já faz planos para o ministério. Folha de $S$. Paulo, São Paulo, 06.10.2013. Disponível em: <http://www1.folha.uol.com.br/ poder/2013/10/1352535-astronauta-vira-socialista-e-ja-faz-planos-para-o-ministerio. shtml>. Acesso em: 20.11.2013.

NOCCIOLI, C. A. M.; PAES, C. C. S. Por que os homens têm peitos? A recontextualização do discurso sobre ciência na Superinteressante. Linguagem em (Dis)curso, Tubarão (SC), v. 12, n. 2, p. 467-494, maio/ago. 2012.

PARAÍSO, M. A. Política da subjetividade docente no currículo da mídia educativa brasileira. Educ. Soc., n.94, jan./abr. 2006. 
PATTO, M. H. S. A produção do fracasso escolar. São Paulo: T.A. Queiroz Editor, 1993.

REBOUÇAS, E. O discurso/escudo da liberdade de expressão dos “donos da mídia”. In: ROMÃO, J. E. E. et al. Classificação indicativa no Brasil: desafios e perspectiva. Brasília: Secretaria Nacional de Justiça, 2006.

RIBEIRO, M. L. S. História da Educação Brasileira: a organização escolar. 15.ed. Campinas: Autores Associados, 1998.

ROMANELLI, O. O. História da Educação no Brasil (1930/1973). 8.ed. Petrópolis: Vozes, 1986.

ROMÃO, J. E. E. A Nova Classificação Indicativa no Brasil: construção democrática de um modelo. In: ROMÃO, J.E.E. et al. Classificaçâo indicativa no Brasil: desafios e perspectiva. Brasília: Secretaria Nacional de Justiça, 2006.

ROMÃO, J. E. E.; CANELA, G.; ALARCON, A. (Coord.). Manual da Nova Classificação Indicativa. Brasília: Ministério da Justiça. Secretaria Nacional de Justiça. Departamento de Justiça, Classificação, Títulos e Qualificação, 2006.

SANTOS, W. G. Ordem burguesa e liberalismo politico. São Paulo: Duas Cidades, 1978.

SAVIANI, D. Vicissitudes e perspectivas do direito à educação no Brasil: abordagem histórica e situação atual. Educ. Soc., v.34, n.124, p.743-760, jul./set. 2013.

SETTON, M. G. J. Juventude, mídias e TICs. In: SPOSITO, M.P. O estado da arte sobre juventude na pós-graduaçâo brasileira: Educação, Ciências Sociais e Serviço Social. Belo Horizonte: Argumentum, 2009. Disponível em: <http://www.emdialogo.uff.br/sites/ default/files/EstadoArte-Vol-2-LivroVirtual.pdf>. Acesso em: 20.12.2013.

SOARES, M.; SÁ, N. Jornalismo domina rede social em protestos. Folha de S. Paulo, São Paulo, 04.07.13, p. A8.

SPOSITO, M. P. Estudos sobre juventude em educação. Revista Brasileira de Educação, Anped, 1997.

TORRES, R. M. Melhorar a qualidade da educação básica? As estratégias do Banco Mundial. In: DE TOMMASI, L. et al. (Org.). O Banco Mundial e as Políticas Educacionais. São Paulo: Cortez, 1996.

WEREBE, M. J. G. Grandezas e Misérias do Ensino no Brasil: 30 anos depois. São Paulo: Ática, 1997.

Recebido em 14 de janeiro de 2015.

Aprovado em 27 de outubro de 2015.

DOI: http://dx.doi.org/10.1590/ES0101-73302015134514 